\title{
On the Dynamics of a Discrete Fractional-Order Cournot-Bertrand Competition Duopoly Game
}

\author{
Abdulrahman Al-Khedhairi $\mathbb{D}^{1},{ }^{1}$ Abdelalim A. Elsadany $\mathbb{D}^{2,3}$ and Amr Elsonbaty $\mathbb{D}^{2,4}$ \\ ${ }^{1}$ Department of Statistics and Operations Research, College of Science, King Saud University, Riyadh, Saudi Arabia \\ ${ }^{2}$ Mathematics Department, College of Science and Humanities Studies in Al-Kharj, Prince Sattam Bin Abdulaziz University, \\ Al-Kharj 11942, Saudi Arabia \\ ${ }^{3}$ Department of Basic Science, Faculty of Computers and Informatics, Suez Canal University, Ismailia 41522, Egypt \\ ${ }^{4}$ Department of Engineering Mathematics and Physics, Faculty of Engineering, Mansoura University, Mansoura 35516, Egypt
}

Correspondence should be addressed to Abdelalim A. Elsadany; aelsadany1@yahoo.com

Received 7 July 2021; Accepted 13 November 2021; Published 7 February 2022

Academic Editor: Ali Ahmadian

Copyright (c) 2022 Abdulrahman Al-Khedhairi et al. This is an open access article distributed under the Creative Commons Attribution License, which permits unrestricted use, distribution, and reproduction in any medium, provided the original work is properly cited.

A discreet fractional-order Cournot-Bertrand competition duopoly game is introduced based on the fractional-order difference calculus of the Caputo operator. The model is designed when players can make long memory decisions. The local stability of equilibrium points is discussed for the proposed model. Some numerical simulations explore the model's bifurcation and chaos by employing bifurcation diagrams, phase portraits, maximal Lyapunov exponents, and time series. According to our findings, the fractional-order parameter has an effect on the game's stability and dynamics.

\section{Introduction}

Game theory is one of the most interesting and complex topics that many researchers are interested in understanding. Game theory is concerned with predicting results for strategic games in which participants, for example, two or more firms competing on the market, have incomplete information on the intentions of others. It is known that the game theory is relevant to the study of corporate behavior in oligopolistic markets, for example, the decisions that companies must make in terms of production and pricing levels, as well as the amount of money invested in research and development. The decision-making mechanism has an important role to play in the process of adjusting the production and profits of firms. Firms typically use one of the following to change their market growth: naïve learning expectation, adaptive learning expectation, limited learning rationality, and local learning approximation. Discrete oligopoly dynamics based on company profit maximizations have been considered [1-7]. Furthermore, these models have been utilized to examine the dynamic characteristics of competitive markets, which has been classified as steady state, periodic, and chaotic [8-14].

Fractional calculus, particularly discrete fractional calculus, has attracted substantial interest in recent decades due to its extensive significance in a wide range of scientific disciplines, including complex systems with memory and heredity. Researchers turned their attention to a discreet fractional calculus and tried to develop a complete theoretical framework for this subject. This is due to the importance of this field in many real issues, such as discreet adaptive systems, biological growth systems, and digital engineering systems, all of which contain memory [15-20]. The discrete difference analogues of classical Caputo and Riemann derivatives have been introduced in [21]. In addition, advances have been made in the study of fractional finite difference equations and the inclusion of fractional difference equations [22-26]. Recently, the stability of fractional time systems in a variety of real-world problems has been investigated. These studies have shown that discrete fractional systems are more realistic to process real systems and have a rich dynamic compared to discrete systems with 
integer-order. Many studies have studied continuous fractional differentiation representing the effects of economic memory that have been presented [27-30] and the references that exist in them as well. The fractional-order difference equation, which is a natural extension of the integerorder difference equation, has long-term memory effects that have been explored in a few studies [25, 31-36]. Recently, the fractional difference calculus was used in the Cournot duopoly game [37] and the Bertrand duopoly game [38]. This reflects the long-term memory effects of Cournot-Bertrand dynamic games in the fractional-order form for the game. Xin et al. [37, 38] investigated the dynamics of the Cournot and Bertrand games, which indicated the market evolution of the two enterprises.

This work is especially interested in the novel discrete fractional-order Cournot-Bertrand duopoly game, which is a modification of the Cournot-Bertrand duopoly game with integer-order [39]. We aim to extend this game to a fractional case and to study the dynamics of the game. As we know, fractional-order calculus is a general form of integerorder calculus, so it has a higher representation for phenomena with a long memory. It can be shown that the fractional differentiation parameter is a vital indicator of the bifurcation path and the chaos that is created and disappeared. We will investigate the dynamics of the discreet fractional-order Cournot-Bertrand duopoly game such as the stability, bifurcation, and chaos of the proposed game. To analyze complexity of the game, explicit stability criteria [40, 41], asymptotic stability criteria [42] and the local stability regions of the boundary and Nash equilibrium points are provided through numerical simulation. The dynamic behavior of the proposed game is illustrated through an exploratory investigation of equilibrium point stability and numerical simulation. In this work, we are analyzing a Cournot-Bertrand duopoly game similar to Wang and $\mathrm{Ma}$ [39], but using a discrete fractional calculus. The equilibrium point structure dynamic reflects economic explanations for the proposed game's market of two enterprises.

The work is organized as seen follows. Section 2 describes the market dynamics of two enterprises using a discrete fractional-order Cournot-Bertrand duopoly game. The Nash equilibrium local stability conditions are established in Section 3. Using numerical simulations, we investigate local bifurcations, maximal Lyapunov exponents, and phase portraits of complex dynamics in Section 4 . Section 5 contains a summary of the findings as well as a few observations.

\section{Preliminaries}

In this section, some preliminaries about fractional-order difference calculus are introduced. On an arbitrary time scale, dynamic behaviors and applications of fractional difference models were investigated in the last decade where delta difference equation was used [40-43].

Assume that a sequence $u(n)$ is given, and the isolated time scale $\aleph a$ is represented in terms of real valued constant $\tau$, i.e., $\{\tau, \tau+1, \tau+2, \ldots$,$\} , such that u: \aleph_{\tau} \longrightarrow \mathbb{R}$. Also, the difference operator is denoted by $\Delta$, where $\Delta u(n)=u(n+1)-u(n)$. Then, we summarize some of the basic definitions related to discrete fractional calculus as follows.

Definition 1. For $\alpha>0$, the fractional sum of order $\alpha$ is given by [21]

$$
\Delta_{\tau}^{-\alpha} u(t)=\frac{1}{\Gamma(\alpha)} \sum_{m=\tau}^{t-\alpha} \frac{\Gamma(t-m)}{\Gamma(t-m-\alpha+1)} u(m), \quad t \in \aleph_{\tau+\alpha} .
$$

Definition 2. The Caputo-like delta difference of order $\alpha$ is defined by $[21,42]$

$$
\begin{aligned}
{ }^{C} \Delta_{\tau}^{\alpha} u(t) & =\Delta_{\tau}^{-(n-\alpha)} \Delta^{n} u(t)=\frac{1}{\Gamma(n-\alpha)} \sum_{m=\tau}^{t-(n-\alpha)} \frac{\Gamma(t-m)}{\Gamma(t-m-n+\alpha+1)} \Delta^{n} u(m), \\
t & \in \aleph_{\tau+\alpha}, n=[\alpha]+1 .
\end{aligned}
$$

Theorem 1 (See [21, 40-43]). In order to solve the delta fractional difference equation,

$$
\left\{\begin{array}{l}
{ }^{C} \Delta_{\tau}^{\alpha} u(t)=f(t+\alpha-1, u(t+\alpha-1)) \\
\Delta^{k} u(t)=u_{k}, n=[\alpha]+1, \quad k=0,1, \ldots, n-1
\end{array}\right.
$$
is

As a result, the corresponding discrete integral equation

$$
u(t)=u_{0}(t)+\frac{1}{\Gamma(\alpha)} \sum_{m=\tau+n-\alpha}^{t-\alpha}(t-\sigma(m))^{(\alpha-1)} f(m+\alpha-1, u(m+\alpha-1)), \quad t \in \aleph_{\tau+n}
$$


where

$$
u_{0}(t)=\sum_{k=0}^{n-1} \frac{\Gamma(t-\tau+1)}{k ! \Gamma(t-\tau-k+1)} \Delta^{k} u(t)
$$

Remark 1. If $\tau=0$, we rewrite discrete integral equation in the following numerical form:

$$
u(n)=u_{0}(t)+\frac{1}{\Gamma(\alpha)} \sum_{m=1}^{n} \frac{\Gamma(n-m+\alpha)}{\Gamma(n-m+1)} f(u(m-1)) .
$$

Theorem 2 (See [40-42]). The linear discrete-time fractional-order system is

$$
{ }^{C} \Delta_{\tau}^{\alpha} U(t)=G U(t+\alpha-1),
$$

where $U(t)=\left(u_{1}(t), u_{2}(t), \ldots, u_{n}(t)\right)^{T}, 0<\alpha \leq 1, G \in \mathbb{R}^{n \times n}$, and $\forall t \in \aleph_{\tau+1-\alpha}$. The zero equilibrium of system (10) is asymptotically stable if

$$
\lambda \in\left\{z \in \mathbb{C}:|z|<\left(2 \cos \frac{|\arg z|-\pi}{2-\alpha}\right)^{\alpha},|\arg z|>\frac{\alpha \pi}{2}\right\},
$$

for all the eigenvalues $\lambda$ of matrix $G$.

\section{Discrete Fractional-Order Cournot-Bertrand Duopoly Game}

According to traditional oligopoly models [1, 6], firms compete in the same strategic variable, such as output (Cournot) or price (Bertrand). A hybrid model, commonly known as the Cournot-Bertrand model [6, 39], permits certain enterprises to compete in output, while others compete in pricing. Real-world market observations that match Cournot-Bertrand behavior have bolstered the model's validity and rapidly growing literature on advancements and applications. Long-term memory effects in dynamic oligopoly games are economically significant $[34,37,38]$. Therefore, we introduce the novel discrete fractional-order Cournot-Bertrand duopoly game, which is a modification of the Cournot-Bertrand duopoly game with integer order. As a consequence, it has a better representation of phenomena with a long memory in oligopoly game. The main goal is to establish out how the fractal parameter affects game dynamics including stability, bifurcation, and chaos.

We suggest a simple Cournot-Bertrand duopoly common oligopoly game [39]. Two enterprises, denoted by the letters $i=1,2$, produced differentiated goods with perfect replacements and set their product pricing based on the same market rule. Assume that $p_{i}(t)$ and $q_{i}(t)$ denote the goods price and quantity output of firm $i$ for the period $t \in Z^{+}$. The inverse demand functions for a variety of products 1 and 2 originate from the representative consumer maximization of the following utility function [39]:

$$
U\left(q_{1}, q_{2}\right)=q_{1}+q_{2}-\frac{1}{2}\left(q_{1}^{2}+2 d q q_{2}+q_{2}^{2}\right)
$$

subjected to restrictions on the budget $p_{1} q_{1}+p_{2} q_{2}=M$. Then, the inverse demand functions is defined as follows:

$$
\left\{\begin{array}{l}
p_{1}=1-q_{1}-\mathrm{d} q_{2}, \\
p_{2}=1-q_{2}-\mathrm{d} q_{1},
\end{array}\right.
$$

where $p_{1}$ and $p_{2}$ represent the pricing of firm 1's and firm 2's items, respectively, and $q_{1}$ and $q_{2}$ are the quantities of products of company 1 and company 2 . The parameter $d \in[0,1]$ is the product differentiation between two firms. Products are homogeneous goods when $d=1$, and each firm has a monopoly case when $d=0$. The demand system can be written in two strategic variables $q_{1}$ and $p_{2}$.

$$
\left\{\begin{array}{l}
p_{1}=1-d-\left(1-d^{2}\right) q_{1}+\mathrm{d} p_{2}, \\
q_{2}=1-p_{2}-\mathrm{d} q_{1} .
\end{array}\right.
$$

Consider that the two companies have the same unit cost $c>0$ and that the cost function has the same linear form:

$$
C_{i}\left(q_{i}\right)=c q_{i}, i=1,2 \text {. }
$$

Thus, the profit functions for firms are given by

$$
\left\{\begin{array}{l}
\pi_{1}=\left(1-d-\left(1-d^{2}\right) q_{1}+\mathrm{d} p_{2}-c\right) q_{1}, \\
\pi_{2}=\left(p_{2}-c\right)\left(1-p_{2}-\mathrm{d} q_{1}\right) .
\end{array}\right.
$$

In the classical dynamical Cournot-Bertrand duopoly game, to decide the corresponding profit-maximizing, every player erroneously believes that its rival's pricing in period $(t+1)$ is the same as in period $(t)$. Therefore, this type of game does not have a long memory effect. The traditional game will be introduced using discrete fractional-order calculus, and the two players will make decisions using a new dynamic adjustment mechanism with long memory and local marginal profit expectation. Thus, the marginal profit of two players is as follows [39]:

$$
\left\{\begin{array}{l}
\frac{\partial \pi_{1}}{\partial q_{1}}=\left(\left(1-d-2\left(1-d^{2}\right) q_{1}+\mathrm{d} p_{2}\right)-c\right), \\
\frac{\partial \pi_{2}}{\partial p_{2}}=\left(1+c-2 p_{2}-\mathrm{d} q_{1}\right) .
\end{array}\right.
$$

Assume that the two businesses have limited information about the market demand function and also their price decision is based on a dynamic adjustment process with limited rationality and a long-term memory effect of marginal profit. In the next step, the firm decides to raise (reduce) the price of its product based on if the long-term marginal profit is greater (less) than zero. As a result, we utilize the dynamic adjustment process for the Cournot-Bertrand game as follows:

$$
\left\{\begin{array}{l}
\Delta^{\alpha} q_{1}=v_{1} q_{1}(t+\alpha-1) \frac{\partial \pi_{1}}{\partial q_{1}}, \\
\Delta^{\alpha} p_{2}=v_{2} p_{2}(t+\alpha-1) \frac{\partial \pi_{2}}{\partial p_{2}},
\end{array}\right.
$$


where $v_{i}$ is the speed of adjustment of firm $i, i=1,2$ and $\alpha \in(0,1)$ denotes a fractional-order number, indicating the long-term memory effect. Thus, the discrete fractional-order Cournot-Bertrand duopoly game is as follows:

$$
\left\{\begin{array}{l}
\Delta^{\alpha} q_{1}=v_{1} q_{1}(t+\alpha-1)\left(1-c-d+\mathrm{d} p_{2}(t+\alpha-1)-2 q_{1}(t+\alpha-1)+2 d^{2} q_{1}(t+\alpha-1)\right) \\
\Delta^{\alpha} p_{2}=v_{2} p_{2}(t+\alpha-1)\left(1+c-2 p_{2}(t+\alpha-1)-\mathrm{d} q_{1}(t+\alpha-1)\right)
\end{array}\right.
$$

Remark 2. When $\alpha=1$, the model (16) devolves to the Wang-Ma model [39]:

$$
\left\{\begin{array}{l}
q_{1}(t+1)=q_{1}(t)+v_{1} q_{1}(t)\left(1-c-d+\mathrm{d} p_{2}(t)-2 q_{1}(t)+2 d^{2} q_{1}(t)\right) \\
p_{2}(t+1)=p_{2}(t)+v_{2} p_{2}(t)\left(1+c-2 p_{2}(t)-\mathrm{d} q_{1}(t)\right)
\end{array}\right.
$$

We will show that the model game parameters, especially the long-term memory effect, have an effect on the long-term dynamic response of our novel game when compared to the Wang-Ma game [39].

In the next sections, several theoretical features corresponding to game (16) are investigated.

\section{The Equilibrium Points and Their Local Stability}

We solve the following equation to find the equilibrium points of game system (16):

$$
\left\{\begin{array}{l}
\left(1-c-d+\mathrm{d} p_{2}(t)-2 q_{1}(t)+2 d^{2} q_{1}(t)\right)=0 \\
\left(1+c-2 p_{2}(t)-\mathrm{d} q_{1}(t)\right)=0
\end{array}\right.
$$

Their four equilibria are $E_{0}=(0,0), E_{1}=(0,1+c / 2)$, $E_{2}=\left(1-c-d / 2\left(1-d^{2}\right), 0\right)$, and $E_{*}=(2-2 c-d+c d / 4-$ $\left.3 d^{2}, 2+2 c-d+c d-d^{2}-2 c d^{2} / 4-3 d^{2}\right)$. In economics, its equilibria mean

(i) The equilibrium $E_{0}$ is trivial equilibrium point

(ii) The equilibrium point $E_{1}$ implies that the best quantity of the first player is $q_{1}^{*}=0$ if the second player sets its optimal product price $p_{2}^{*}=1+c / 2$. Likewise, the second player's best price is $p_{2}^{*}=1+c / 2$ if the player uses a zero-price approach. Clearly, $E_{1}$ is a border equilibrium point that corresponds to the pure monopoly.

(iii) The $E_{2}$ equilibria indicates that the best quantity of the first player is $q_{1}^{*}=1-c-d / 2\left(1-d^{2}\right)$ if the second company determines the best good price $p_{2}^{*}=0$. Likewise, the first company's best pricing is $q_{1}^{*}=1-c-d / 2\left(1-d^{2}\right)$ if the company uses a zeroprice approach. Clearly, $E_{2}$ is a border equilibrium point.

(iv) The equilibrium $E_{*}$ indicates two enterprises will preserve their equilibrium quantity and pricing jointly since no enterprise can gain an advantage by deviating unilaterally from its own equilibrium. Clearly, the point $E_{*}$ is a Nash equilibrium. The complexity of system (16) will be explored. First, the Jacobian matrix of system (16) is computed at a given equilibrium point $\bar{E}=\left(q_{1}^{*}, p_{2}^{*}\right)$, and it can be expressed as

$$
J\left(q_{1}, p_{2}\right)=\left(\begin{array}{cc}
v_{1}\left(1-c-d+\mathrm{d} p_{2}^{*}+4\left(d^{2}-1\right) q_{1}^{*}\right) & v_{1} d q_{1}^{*} \\
-v_{2} d p_{2}^{*} & v_{2}\left(1+c-4 p_{2}^{*}-\mathrm{d} q_{1}^{*}\right)
\end{array}\right) .
$$

Then, the following theorems are presented to clarify linear stability for each equilibrium point in the model.

The trivial equilibrium point $E_{0}$ is unstable.

Proof. The Jacobian matrix's eigenvalues at $E_{0}$ can be demonstrated to be $\left(v_{2}(1+c), v_{1}(1-c-d)\right)$, which indicate that one of them is always positive, and thus, the conditions of asymptotic stability in Theorem 2 are not satisfied.
The equilibrium point $E_{1}$ is asymptotically stable if

$$
\begin{gathered}
\left.v_{1}(c d+2-2 c-d)\right)<0, v_{2}(1+c) \\
\left.\quad<2^{\alpha}, \mid v_{1}(c d+2-2 c-d)\right) \mid<2^{\alpha+1} .
\end{gathered}
$$

Proof. The eigenvalues of Jacobian matrix at $E_{1}$ are $\left(-v_{2}(1+c), 1 / 2 v_{1}(c d+2-2 c-d)\right)$, which means that the conditions of asymptotic stability in Theorem 2 are satisfied 
if the second eigenvalue has a negative sign, and also, the modulus of the two eigenvalues is bounded by $2^{\alpha}$ and $2^{\alpha+1}$, respectively. Figure 1 shows stability regions in some three and two-dimensional spaces of model's parameters, whereas
Figure 2 shows the resulting time series when the values of parameters are selected in stable regions of $E_{1}$.

The equilibrium $E_{2}$ is asymptotically stable if and only if

$$
\begin{aligned}
& v_{1}(c+d-1)<0, v_{2}\left(2 c d^{2}-c d-2 c+d^{2}+d-2\right)>0, \quad 0<d<1, \\
& \left|v_{2}(c+d-1)\right|<2^{\alpha}, \\
& v_{2}\left(2 c d^{2}-c d-2 c+d^{2}+d-2\right)<2^{\alpha+1}\left(1-d^{2}\right) .
\end{aligned}
$$

Proof. The eigenvalues of Jacobian matrix at $E_{2}$ are $\left(v_{1}(c+d-1), v_{2}\left(2 c d^{2}-c d-2 c+d^{2}+d-2\right) / 2\left(d^{2}-1\right)\right)$, which means that the conditions of asymptotic stability in Theorem 2 are satisfied if the two eigenvalues have negative signs, and also, the modulus of the two eigenvalues is bounded by $2^{\alpha}$ and $2^{\alpha+1}\left(1-d^{2}\right)$, respectively.

However, detailed numerical examinations in space of promoters show that the aforementioned conditions cannot be simultaneously achieved at feasible values of parameters, and therefore, due to the impossibility of numerically satisfying the above conditions, the equilibrium point $E_{2}$ is unstable.

Finally, the Nash equilibrium point $E_{*}$ has long complicated expressions for its associated eigenvalues which renders numerical investigations of regions of stability inevitable. Figure 3 shows stability regions in some three and two-dimensional spaces of model's parameters, whereas Figure 4 illustrates the resulting time series when the values of parameters are selected in stable regions of $E_{*}$.

\section{Numerical Simulations}

In this section, the complex dynamic features of the discrete fractional Cournot-Bertrand model (16) are investigated using various methods such as bifurcation diagrams, phase portraits, and MLE. The effects of major model parameters are investigated. For the present fractional discrete model (16) using theorem (4), the system (16) can be numerically rewritten as follows:

$$
\left\{\begin{array}{l}
q_{1}(n)=q_{1}(0)+\frac{1}{\Gamma(\alpha)} \sum_{i=1}^{n} \frac{\Gamma(n-i+\alpha)}{\Gamma(n-i+1)} v_{1} q_{1}(i-1)\left(\left(1-c-d+\mathrm{d} p_{2}(i-1)-2 q_{1}(i-1)+2 d^{2} q_{1}(i-1)\right)\right. \\
p_{2}(n)=p_{2}(0)+\frac{1}{\Gamma(\alpha)} \sum_{i=1}^{n} \frac{\Gamma(n-i+\alpha)}{\Gamma(n-i+1)} v_{2} p_{2}(i-1)\left(1+c-2 p_{2}(i-1)-\mathrm{d} q_{1}(i-1)\right)
\end{array}\right.
$$

The initial point $\left(q_{1}(0), p_{2}(0)\right)=(0.2,0.1)$ is used in the following simulations. In particular, the complicated dynamics exhibited by the model are examined via using the bifurcation diagram, phase portraits, and maximal Lyapunov exponent (MLE). The Lyapunov exponent for a one-dimensional map can be calculated by calculating the average value for perturbations from the trajectory over a time interval. The Lyapunov exponents for an $n$-dimensional mapping can be obtained using the eigenvalues of the product of Jacobian matrices for integerorder systems. In order to approximate the values of Lyapunov exponents of the discrete fractional model (16), the Jacobian matrix method which has been introduced by $\mathrm{Wu}$ and Baleanu [44] can be employed $[45,46]$. In the following part, the numerical analysis will look at the effects of the model's main parameters, as well as the effects of long-term memory and adjustment speeds.
First, the influences of parameter $v_{1}$ in integer-order and fractional-order cases are explored. Figure 5 shows bifurcation diagrams and MLE plots versus parameter $v_{1}$ along with examples of phase portraits at some selected values of parameters.

Second, the influences of parameter $v_{2}$ in integer-order and fractional-order cases are explored. Figure 6 shows bifurcation diagrams and MLE plots versus parameter $v_{2}$, along with examples of phase portraits at some selected values of parameters.

Third, the influences of parameter $d$ in integer-order and fractional-order cases are explored. Figure 7 shows bifurcation diagrams and MLE plots versus parameter $d$ along with examples of phase portraits at some selected values of parameters.

Finally, the effects of fractional-order $\alpha$ are explored. Figure 8 shows bifurcation diagrams and MLE plots versus parameter $\alpha$ along with examples of phase portraits at some selected values of parameters. 


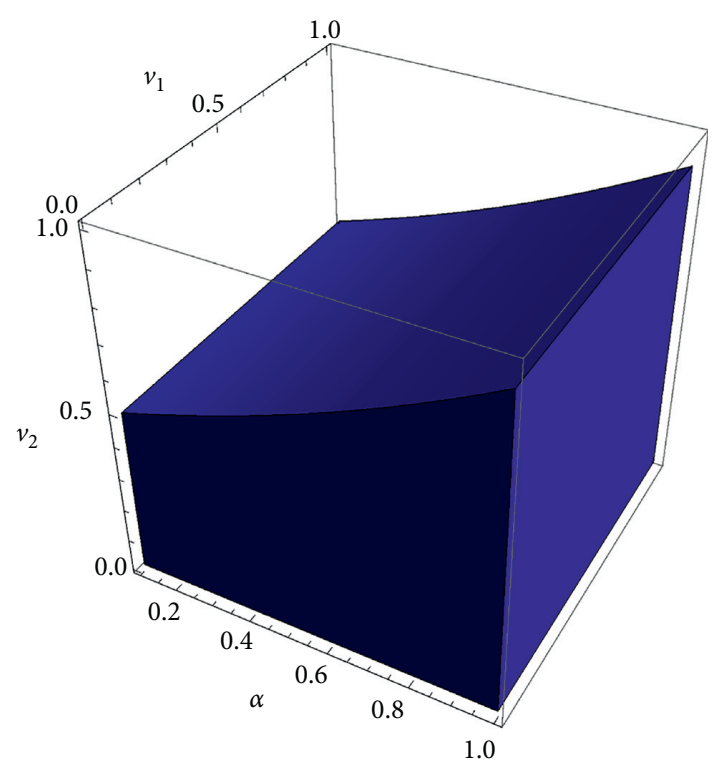

(a)

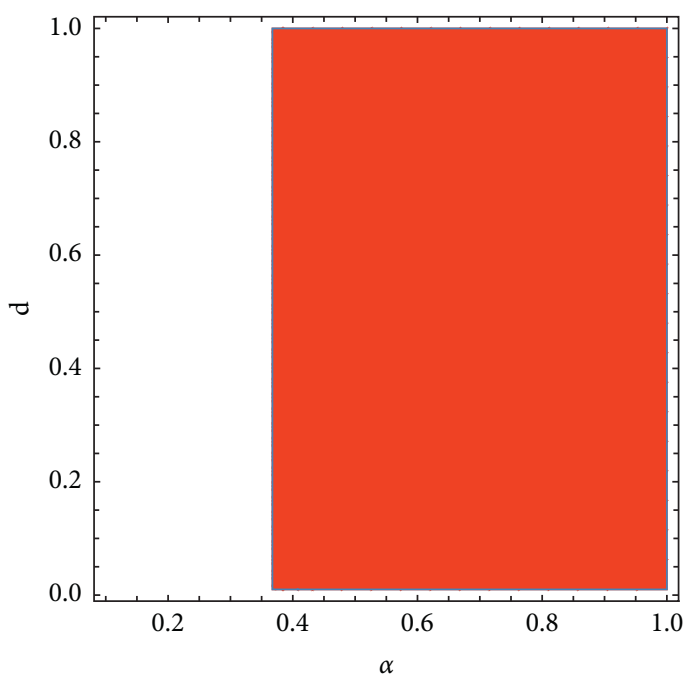

(b)

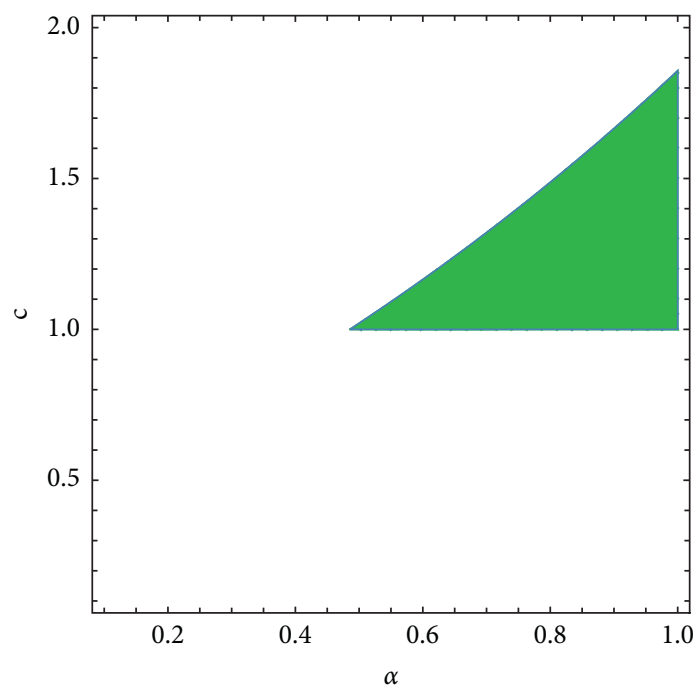

(c)

FIgURE 1: Stability regions of equilibrium point $E_{1}$ in some three and two-dimensional spaces of model's parameters when (a) $c=1.15 ; d=0.6$, (b) $c=1.15 ; v_{1}=0.5 ; v_{2}=0.6$, and (c) $d=0.5 ; v_{1}=0.7 ; v_{2}=0.7$.

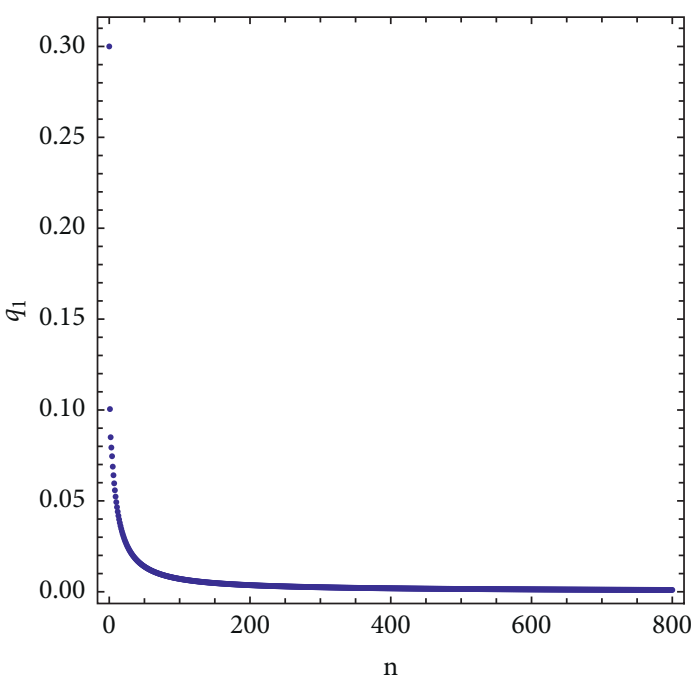

(a)

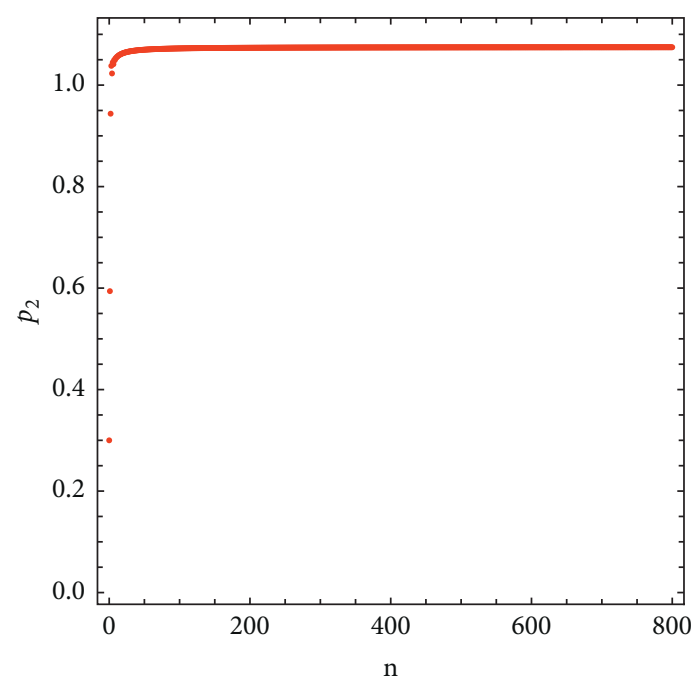

(b)

Figure 2: Time series of model (16) at $c=1.15, d=0.5, v_{1}=0.7, v_{2}=0.7$, and $\alpha=0.9$. 


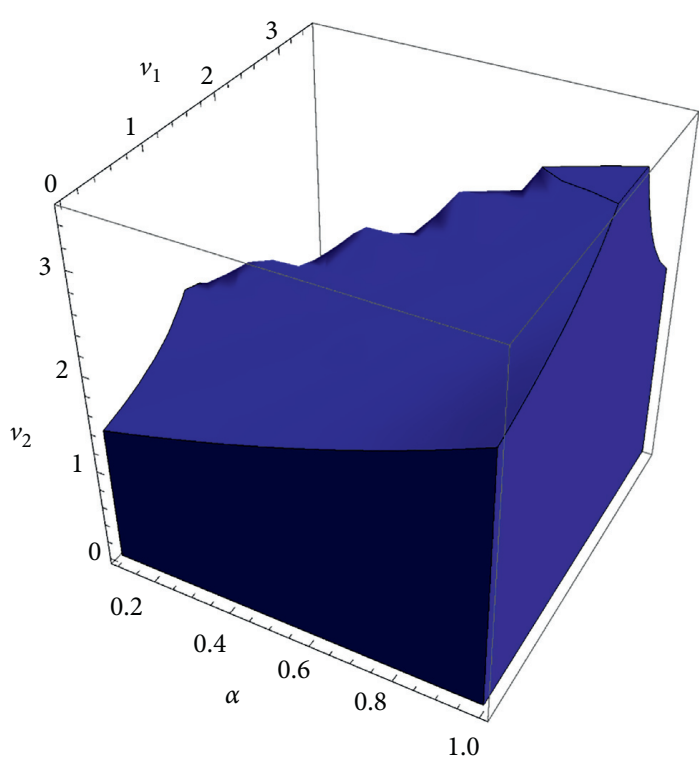

(a)

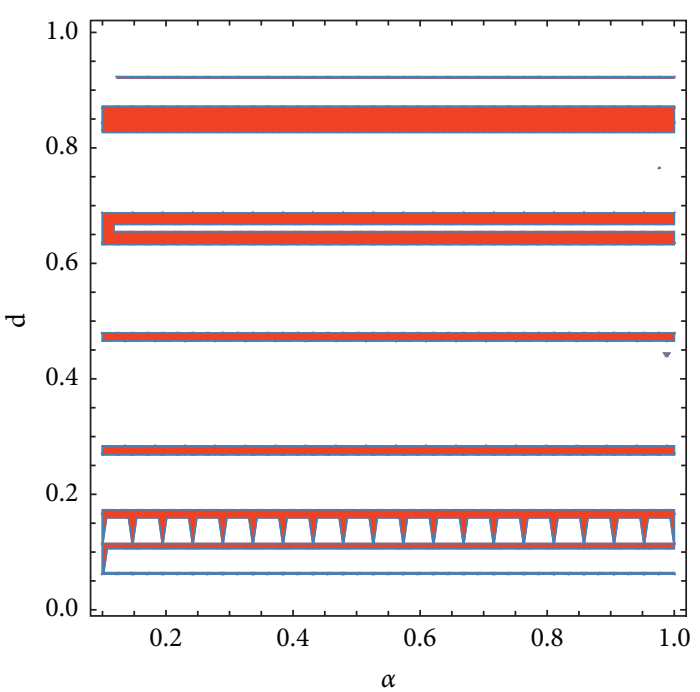

(b)

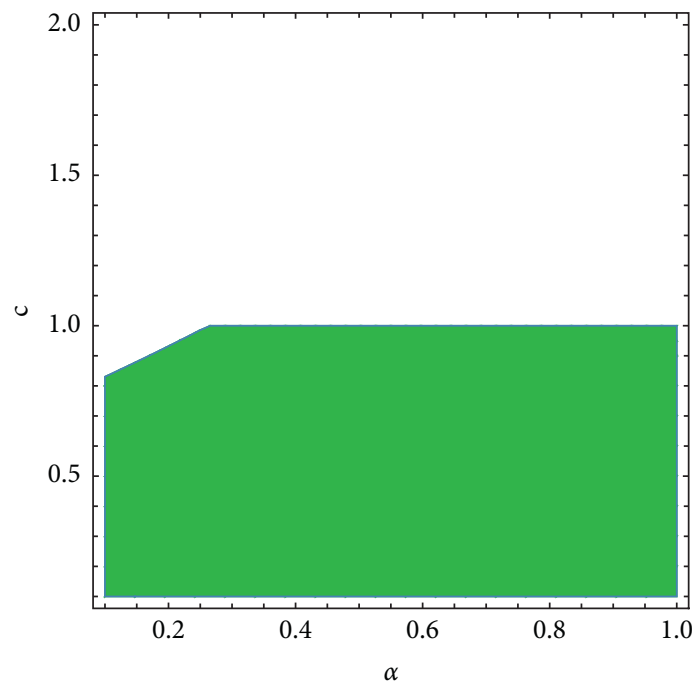

(c)

Figure 3: Stability regions of equilibrium point $E_{*}$ in some three and two-dimensional spaces of model's parameters when (a) $c=0.15 ; d=0.8$, (b) $c=1 ; v_{1}=0.4 ; v_{2}=0.7$, and (c) $d=0.5 ; v_{1}=0.3 ; v_{2}=0.6$. 


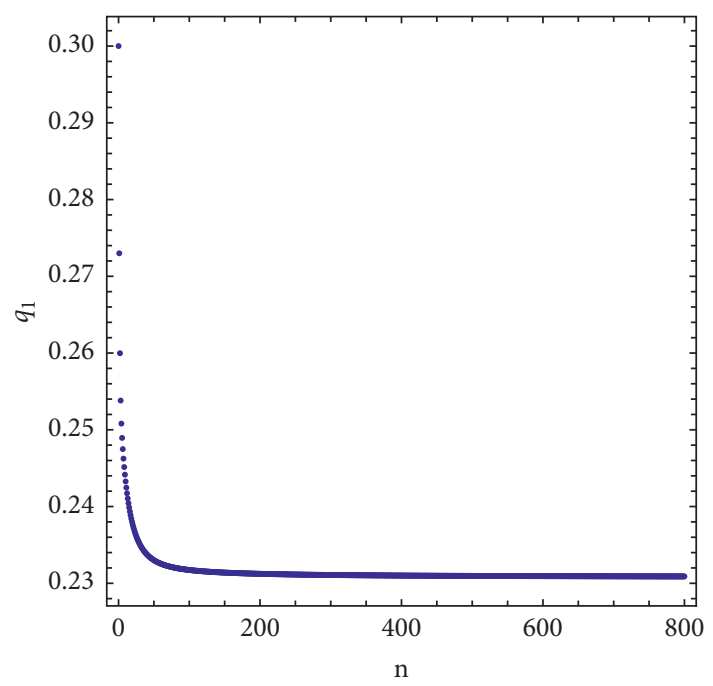

(a)

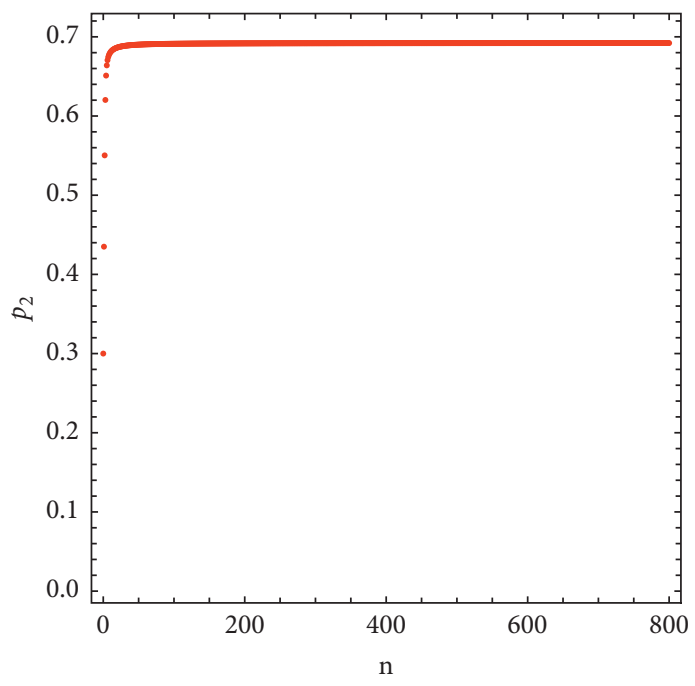

(b)

Figure 4: Time series of model (16) at $c=0.5, d=0.5, v_{1}=0.3, v_{2}=0.6$, and $\alpha=0.9$.

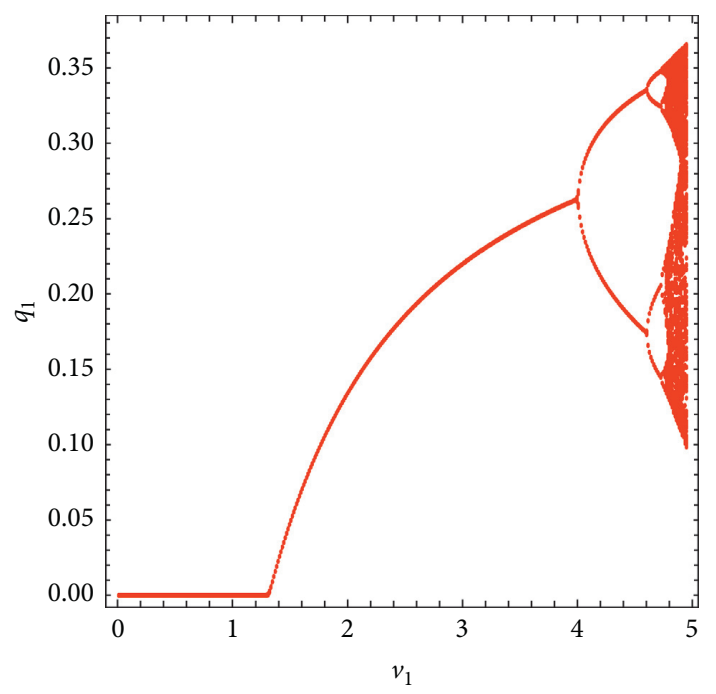

(a)

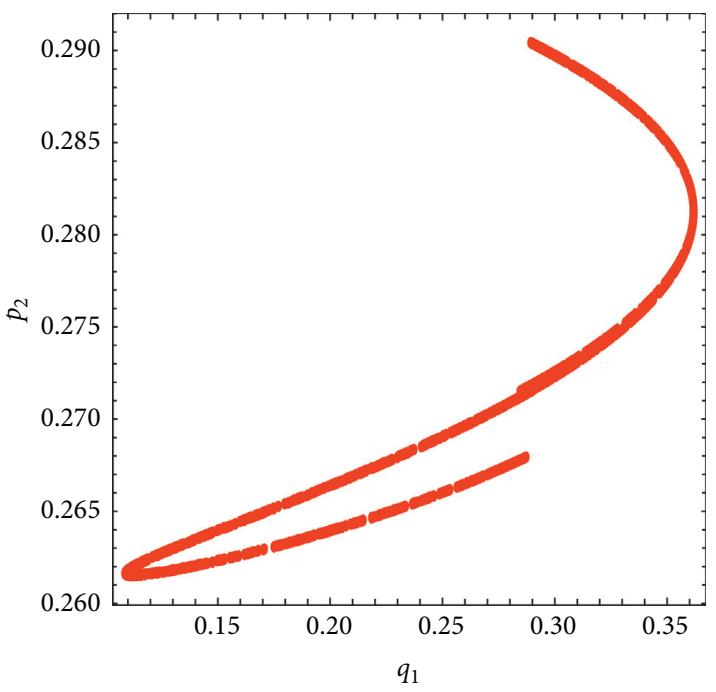

(c)

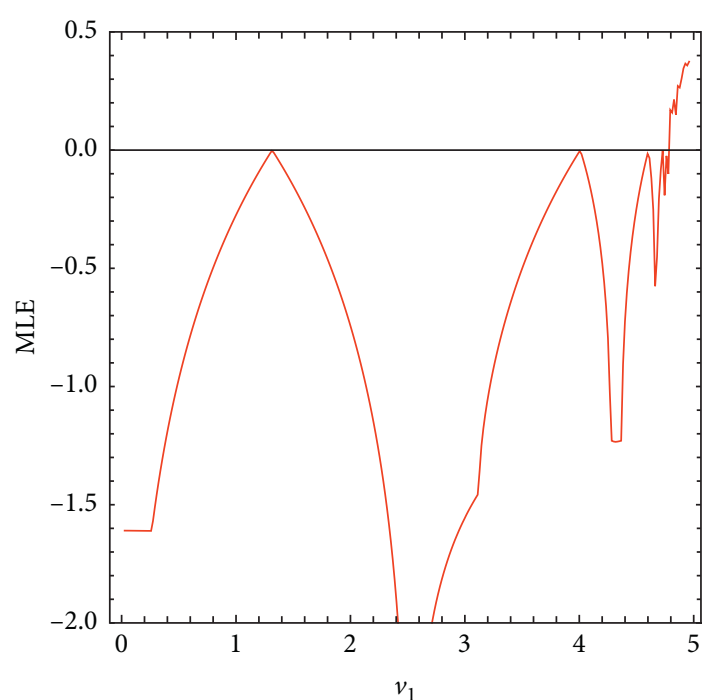

(b)

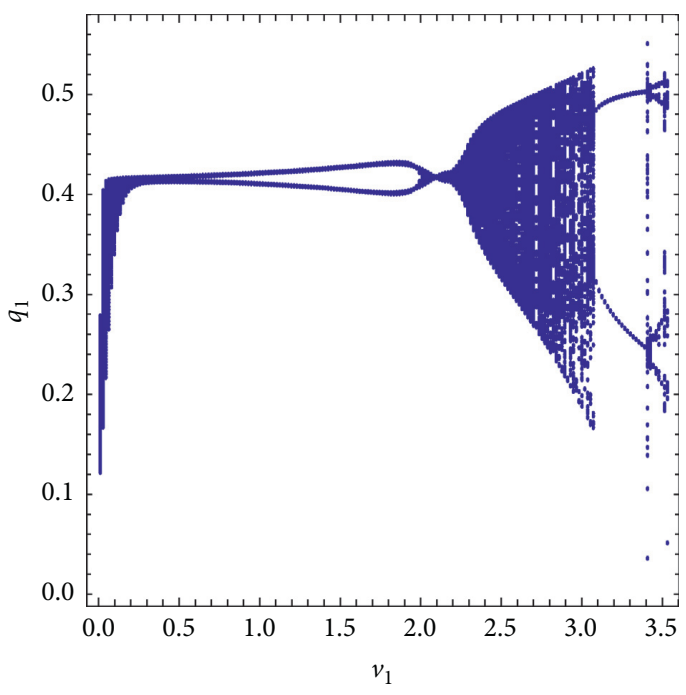

(d)

Figure 5: Continued. 


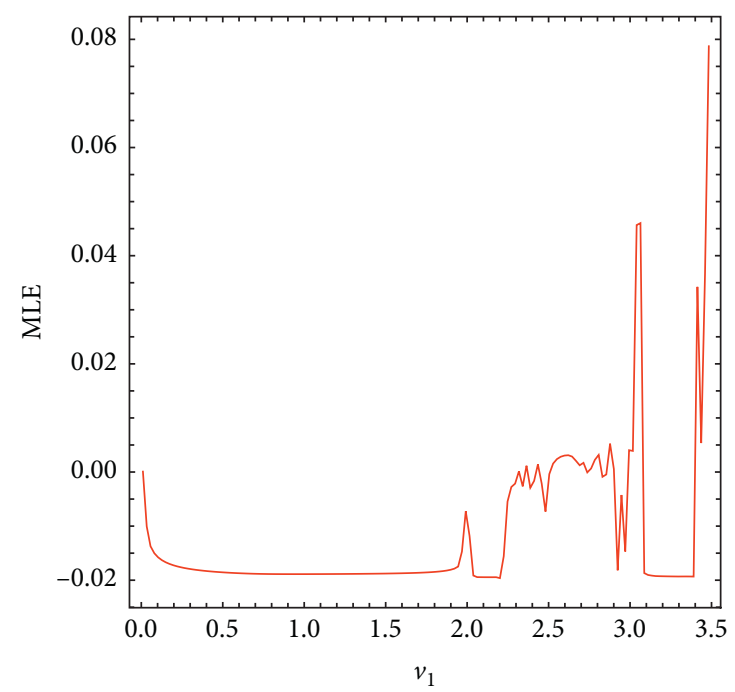

(e)

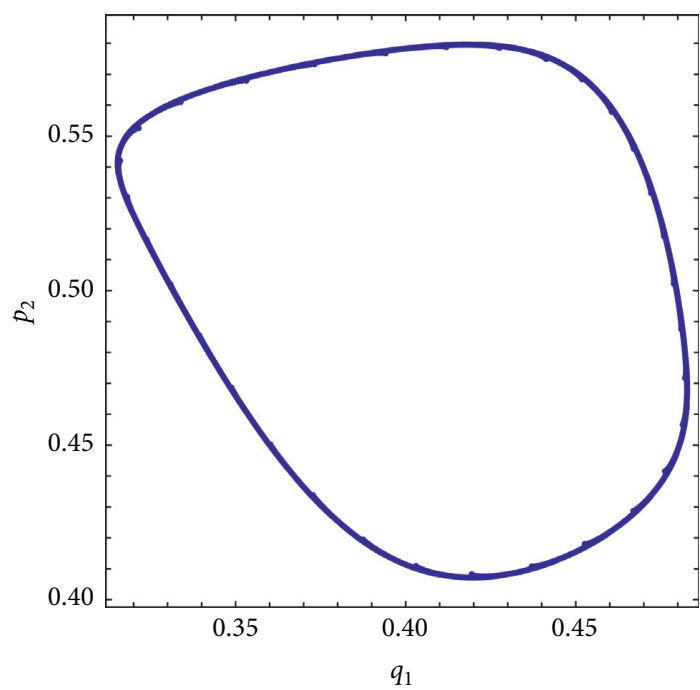

(f)

Figure 5: (a) Bifurcation diagram of system (16) vs. $v_{1}$ at $c=0.1 ; d=0.2 ; v_{2}=2 ; \alpha=1$. (b) MLE plot of system (16) vs. $v_{1}$ at $c=0.1 ; d=0.2 ; v_{2}=2 ; \alpha=1$.(c) Phase portrait of system (16) at $c=0.1 ; d=0.2 ; v_{1}=4.9 ; v_{2}=2 ; \alpha=1$. (d)-(f) similar to (a)-(c) but for $\alpha=0.95$.

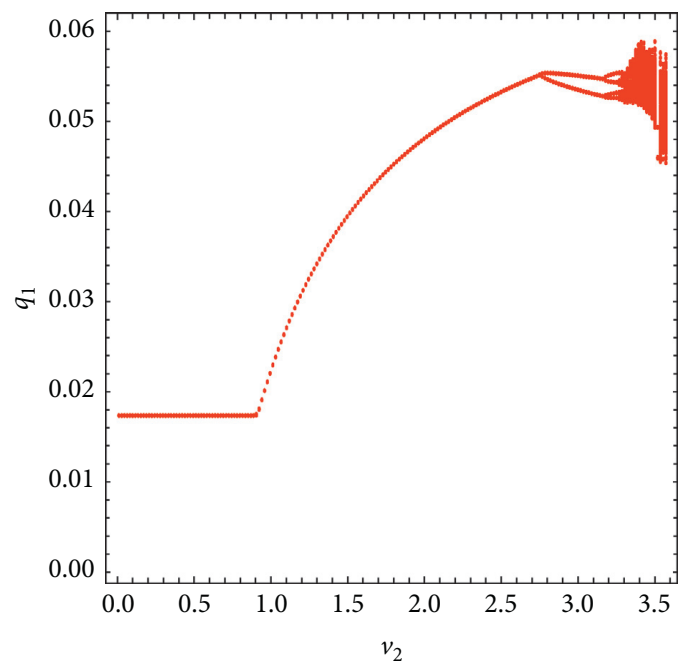

(a)

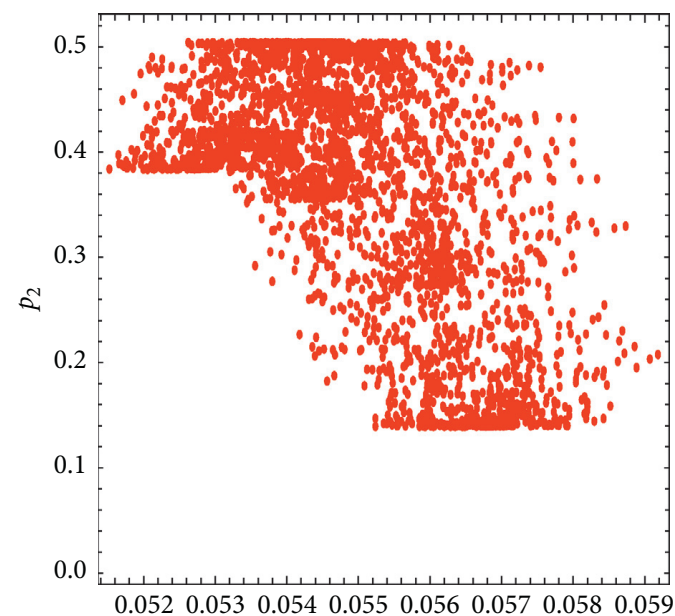

$q_{1}$

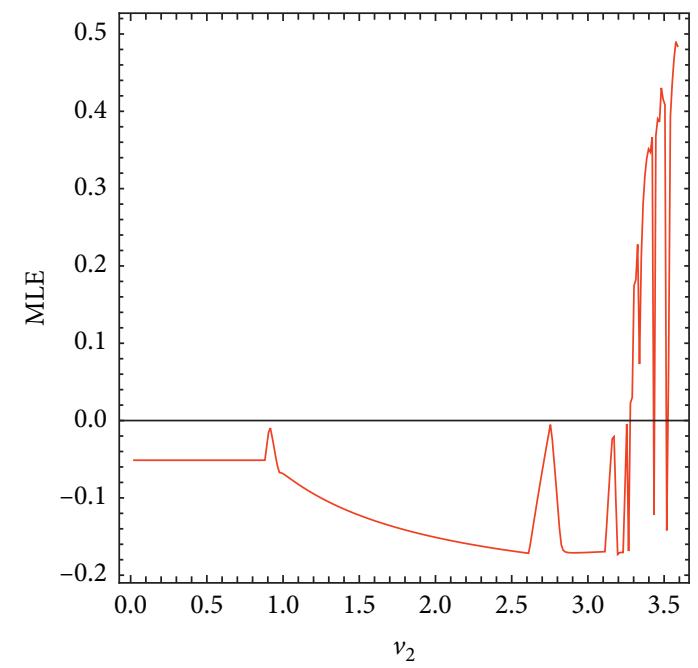

(b)

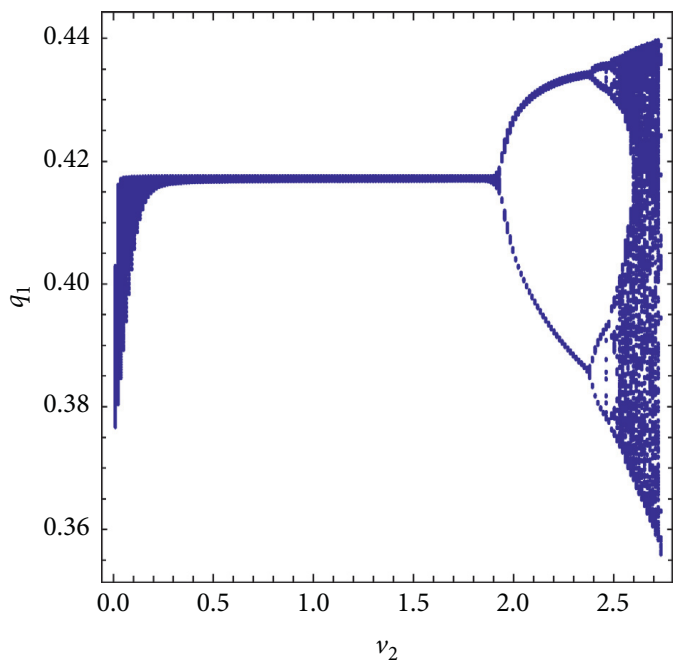

(d)

Figure 6: Continued. 


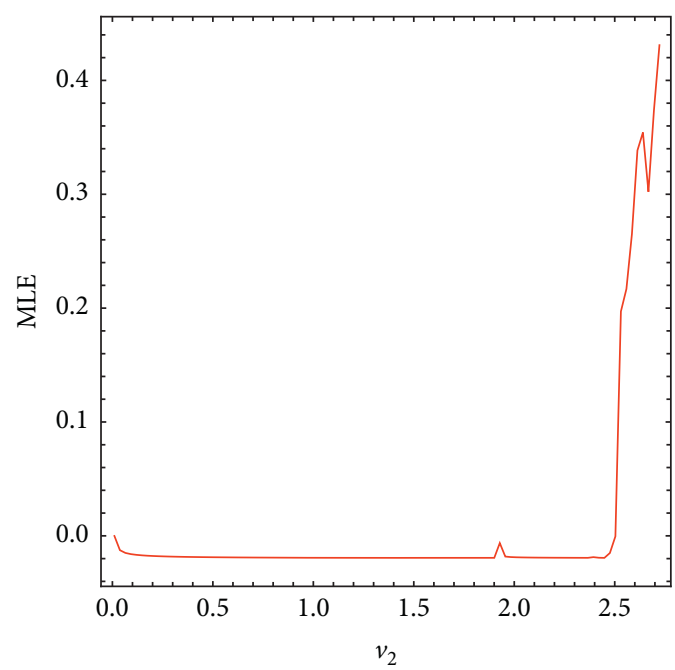

(e)

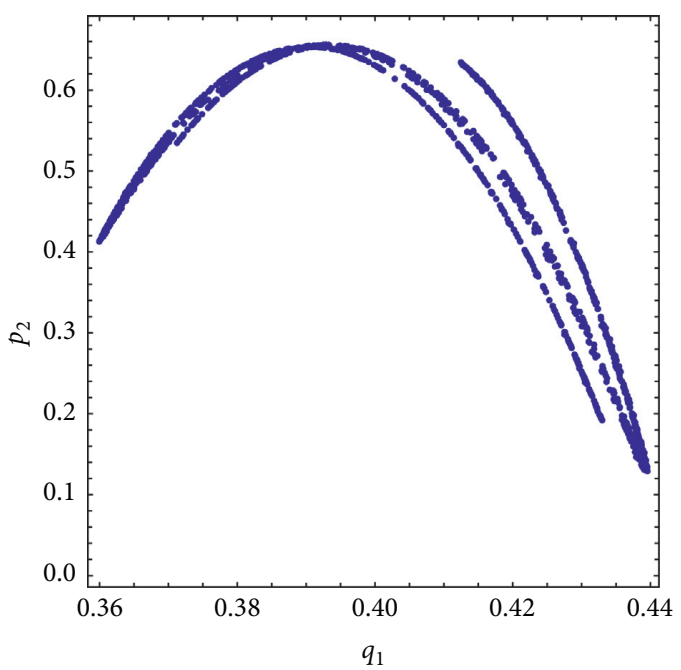

(f)

Figure 6: (a) Bifurcation diagram of system (16) vs. $v_{2}$ at $c=0.1 ; d=0.2 ; v_{1}=1.5 ; \alpha=1$. (b) MLE plot of system (16) vs. $v_{2}$ at $c=0.1 ; d=0.2 ; v_{1}=1.5 ; \alpha=1$. (c) Phase portrait of system (16) at $c=0.1 ; d=0.2 ; v_{1}=1.5 ; v_{2}=3.4 ; \alpha=1$. (d) $-(\mathrm{f})$ similar to (a)-(c) but for $\alpha=0.95$.

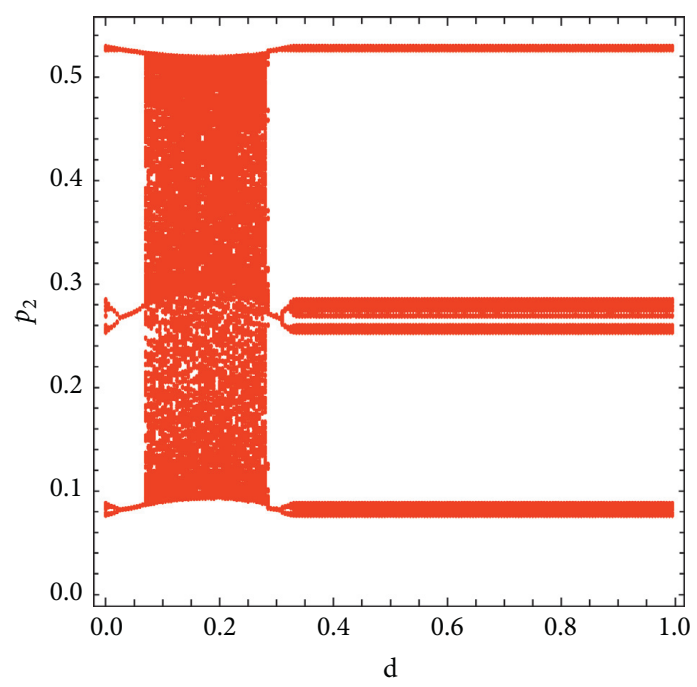

(a)

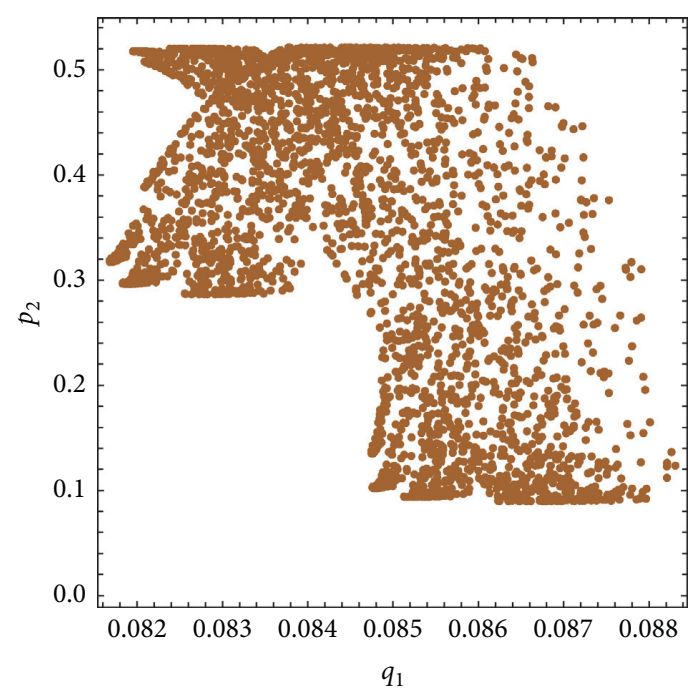

(c)

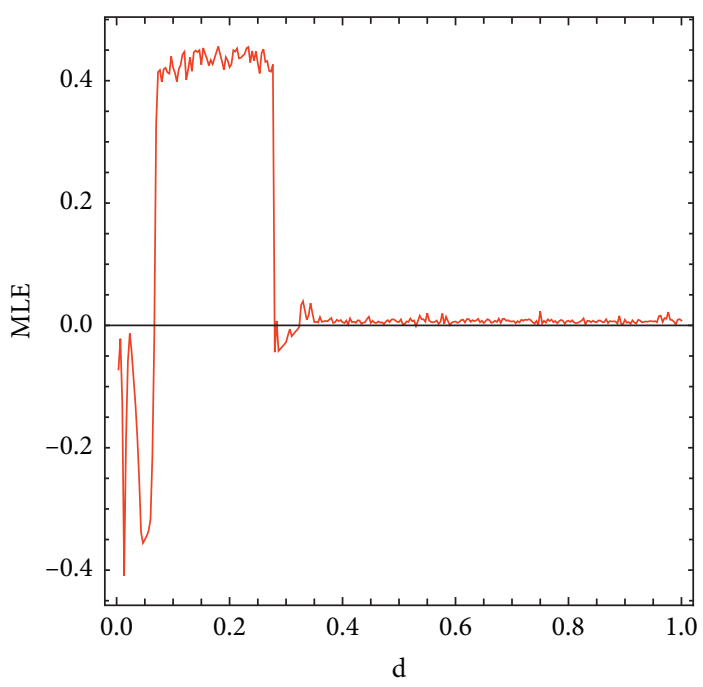

(b)

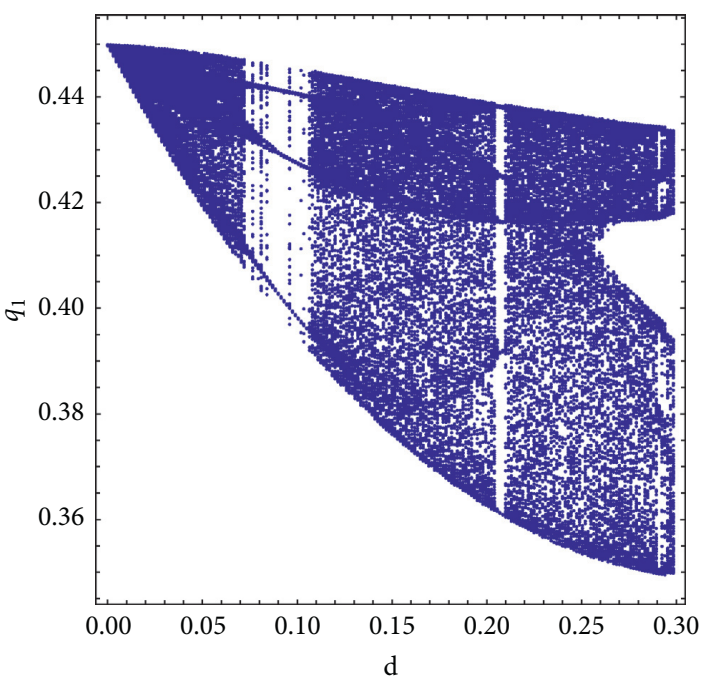

(d)

Figure 7: Continued. 


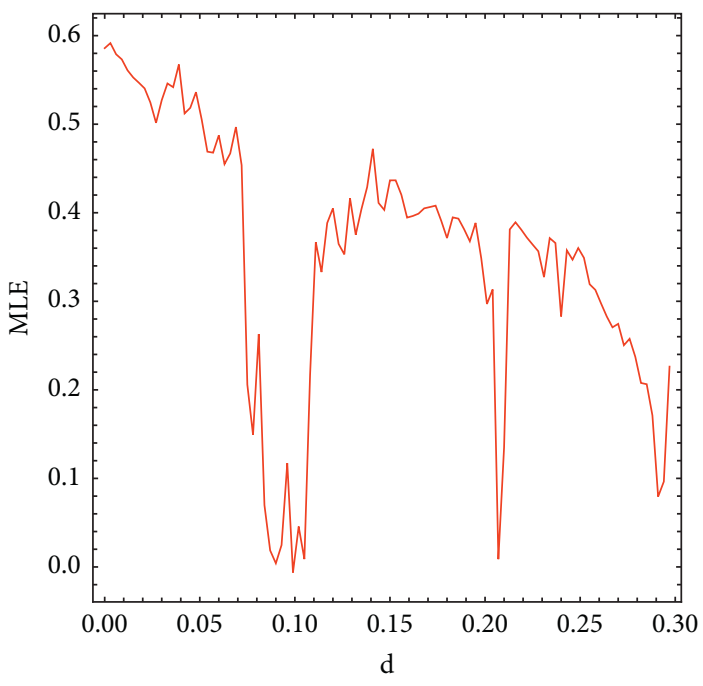

(e)

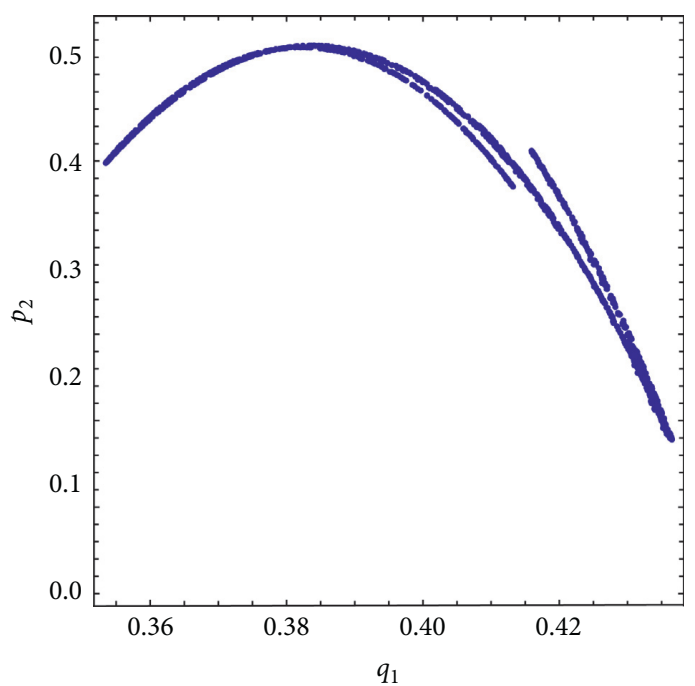

(f)

Figure 7: (a) Bifurcation diagram of system (16) vs. $d$ at $c=0.1 ; v_{1}=1.5 ; v_{2}=3.5 ; \alpha=1$. (b) MLE plot of system (16) vs. $d$ at $c=0.1 ; v_{1}=1.5 ; v_{2}=3.5 ; \alpha=1$. (c) Phase portrait of system (16) at $c=0.1 ; d=0.1 ; v_{1}=1.5 ; v_{2}=3.5 ; \alpha=1$. (d)-(f) similar to (a)-(c) but for $\alpha=0.95$.

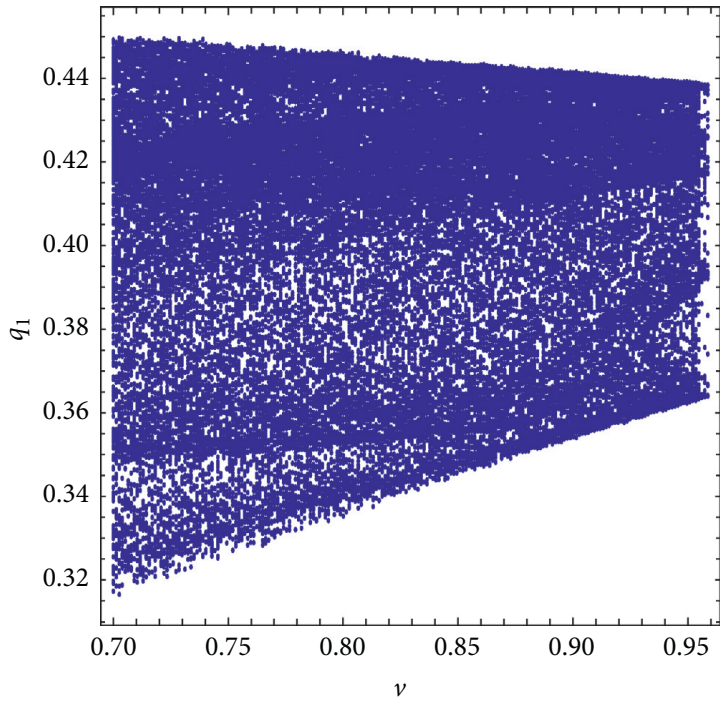

(a)

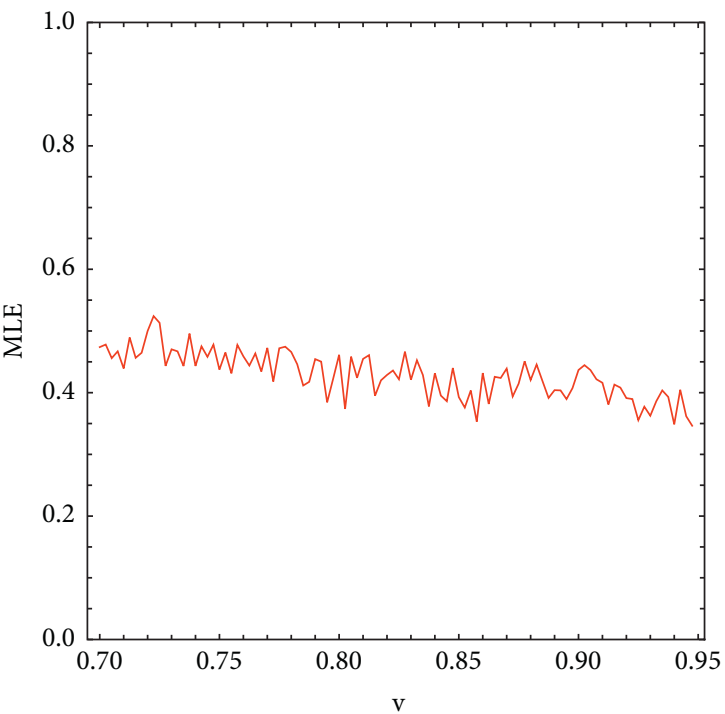

(b)

Figure 8: Continued. 


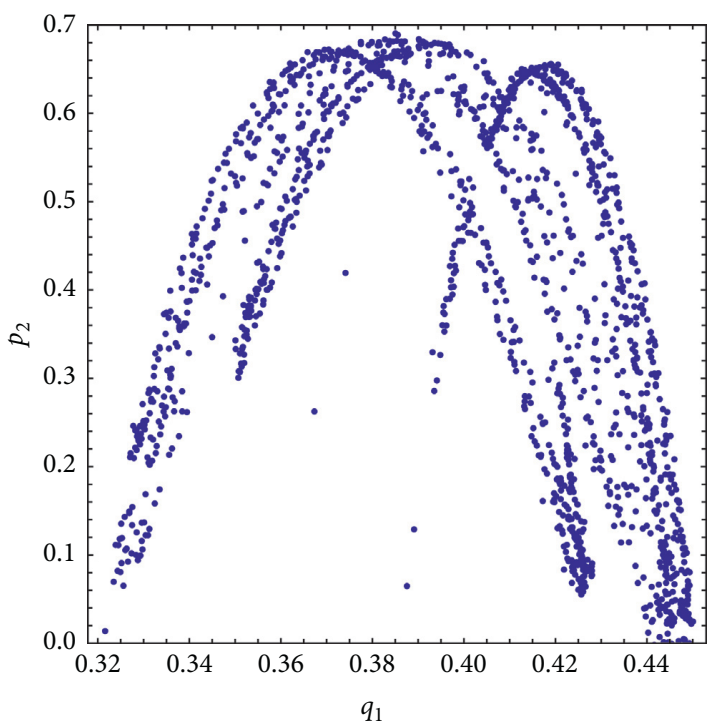

(c)

Figure 8: (a) Bifurcation diagram of system (16) vs. $\alpha$ at $c=0.1 ; d=0.2 ; v_{1}=1.5 ; v_{2}=2.67$. (b) MLE plot of system (16) vs. $\alpha$ at $c=0.1 ; d=0.2 ; v_{1}=1.5 ; v_{2}=2.67$. (c) Phase portrait of system (16) at $c=0.1 ; d=0.2 ; v_{1}=1.5 ; v_{2}=2.67 ; \alpha=0.7$.

\section{Conclusion}

The new fractional-order Cournot-Bertrand game based on a long memory effect is proposed. The stability of the game's equilibrium points, including the Nash equilibria, has been explored both qualitatively and numerically. Bifurcation, phase portraiture, time series, and maximal Lyapunov exponents' diagrams have been used to analyze the complex dynamic characteristics of the proposed game. When we compared our new model to the WangMa model [39], we found that the game parameters, especially the long-term memory influence, had an effect on the long-term dynamic response of our novel model. This is important for understanding the performance of the duopoly game with the long-term memory effect. According to our findings, the Cournot-Bertrand duopoly game with the long-term memory effect is more efficient than the duopoly game without long-term memory impact from economic viewpoint. As a consequence, we advise researchers to investigate the competitive games of long-term memory impact further.

\section{Data Availability}

No data were used to support this study.

\section{Conflicts of Interest}

The authors declare that they have no conflicts of interest.

\section{Acknowledgments}

The authors would like to express sincere gratitude to all referees and editors for their valuable comments and constructive suggestion to the earlier version of this study. They would also like to thank the Deanship of Scientific Research at Prince Sattam bin Abdulaziz University, Al-Kharj, Saudi Arabia.

\section{References}

[1] T. Puu, "Chaos in duopoly pricing," Chaos, Solitons \& Fractals, vol. 1, no. 6, pp. 573-581, 1991.

[2] G. I. Bischi and A. Naimzada, "Global analysis of a dynamic duopoly game with bounded rationality," in Advances in Dynamic Games and Applications, J. A. Filar, V. Gaitsgory, and K. Mizukami, Eds., vol. 5, Basel, Switzerland, Birkhauser, 2000.

[3] G. I. Bischi and M. Kopel, "Equilibrium selection in a nonlinear duopoly game with adaptive expectations," Journal of Economic Behavior \& Organization, vol. 46, no. 1, pp. 73-100, 2001.

[4] A. Agliari, L. Gardini, and T. Puu, "Global bifurcations of basins in a triopoly game," International Journal of Bifurcation and Chaos, vol. 12, no. 10, pp. 2175-2207, 2002.

[5] H. N. Agiza and A. A. Elsadany, "Nonlinear dynamics in the cournot duopoly game with heterogeneous players," Physica A: Statistical Mechanics and Its Applications, vol. 320, pp. 512-524, 2003.

[6] G. I. Bischi, C. Chiarella, M. Kopel, and F. Szidarovszky, Nonlinear Oligopolies: Stability and Bifurcations, Springer Science \& Business Media, Berlin, Germany, 2009.

[7] H. N. Agiza and A. A. Elsadany, "Chaotic dynamics in nonlinear duopoly game with heterogeneous players," Applied Mathematics and Computation, vol. 149, no. 3, pp. 843-860, 2004.

[8] S. Askar, "The rise of complex phenomena in Cournot duopoly games due to demand functions without inflection points," Communications in Nonlinear Science and Numerical Simulation, vol. 19, no. 6, pp. 1918-1925, 2014.

[9] E. Ahmed, G. A. Ashry, and S. S. Askar, "On multi-objective optimization and game theory in production management," 
International Journal of Nonlinear Science, vol. 24, pp. 29-33, 2017.

[10] L. Cerboni Baiardi and A. K. Naimzada, "An oligopoly model with rational and imitation rules," Mathematics and Computers in Simulation, vol. 156, pp. 254-278, 2019.

[11] A. Ibrahim, "Local stability condition of the equilibrium of a constraint pro $\mathrm{t}$ maximization duopoly model," AIP Conference Proceedings, vol. 2138, Article ID 030020, 2019.

[12] J. Andaluz, A. A. Elsadany, and G. Jarne, "Dynamic Cournot oligopoly game based on general isoelastic demand," Nonlinear Dynamics, vol. 99, no. 2, pp. 1053-1063, 2020.

[13] S. S. Askar and A. Al-Khedhairi, "Dynamic investigations in a duopoly game with price competition based on relative profit and profit maximization," Journal of Computational and Applied Mathematics, vol. 367, Article ID 112464, 2020.

[14] W. Zhou, Y. Cao, A. Elsonbaty, A. A. Elsadany, and T. Chu, "Bifurcation analysis of a bounded rational duopoly game with consumer surplus," International Journal of Bifurcation and Chaos, vol. 31, no. 7, Article ID 2150097, 2021.

[15] I. Podlubny, Fractional Differential Equations: An Introduction to Fractional Derivatives, Fractional Differential Equations, to Methods of Their Solution and Some of Their Applications, Elsevier, Amsterdam, Netherlands, 1999.

[16] A. A. Kilbas, H. M. Srivastava, and J. J. Trujillo, Theory and Applications of Fractional Differential Equations, Elsevier, Amsterdam, Netherlands, 2006.

[17] I. Petras, Fractional-order Nonlinear Systems: Modeling, Analysis and Simulation, Springer Science Business Media, Berlin, Germany, 2011.

[18] C. Goodrich and A. C. Peterson, Discrete Fractional Calculus, Springer, Berlin, Germany, 2015.

[19] P. Ostalczyk, Discrete Fractional Calculus: Applications in Control and Image Processing, World Scientific, Singapore, 2015.

[20] H. Sun, Y. Zhang, D. Baleanu, W. Chen, and Y. Chen, "A new collection of real world applications of fractional calculus in science and engineering," Communications in Nonlinear Science and Numerical Simulation, vol. 64, pp. 213-231, 2018.

[21] T. Abdeljawad, "On Riemann and caputo fractional differences," Computers \& Mathematics with Applications, vol. 62, no. 3, pp. 1602-1611, 2011.

[22] A. E. M. El-Misiery and E. Ahmed, "On a fractional model for earthquakes," Applied Mathematics and Computation, vol. 178, no. 2, pp. 207-211, 2006.

[23] K. Diethelm, "A fractional calculus based model for the simulation of an outbreak of dengue fever," Nonlinear Dynamics, vol. 71, no. 4, pp. 613-619, 2013.

[24] T. Abdeljawad, S. Banerjee, and G. C. Wu, "Discrete tempered fractional calculus for new chaotic systems with short memory and image encryption," Optik, vol. 218, Article ID 163698, 2020.

[25] L.-L. Huang, J. H. Park, G.-C. Wu, and Z.-W. Mo, "Variableorder fractional discrete-time recurrent neural networks," Journal of Computational and Applied Mathematics, vol. 370, Article ID 112633, 2020.

[26] Y. Li, C. Sun, H. Ling, A. Lu, and Y. Liu, "Oligopolies price game in fractional order system," Chaos, Solitons \& Fractals, vol. 132, Article ID 109583, 2020.

[27] W.-C. Chen, "Nonlinear dynamics and chaos in a fractionalorder financial system," Chaos, Solitons \& Fractals, vol. 36, no. 5, pp. 1305-1314, 2008.

[28] Z. Wang, X. Huang, and G. Shi, "Analysis of nonlinear dynamics and chaos in a fractional order financial system with time delay," Computers \& Mathematics with Applications, vol. 62, no. 3, pp. 1531-1539, 2011.

[29] V. E. Tarasov, "No nonlocality. no fractional derivative," Communications in Nonlinear Science and Numerical Simulation, vol. 62, pp. 157-163, 2018.

[30] A. Yousefpour, H. Jahanshahi, J. M. Munoz-Pacheco, S. Bekiros, and Z. Wei, "A fractional-order hyper-chaotic economic system with transient chaos," Chaos, Solitons \& Fractals, vol. 130, Article ID 109400, 2020.

[31] G. C. Wu and D. Baleanu, "Discrete fractional logistic map and its chaos," Nonlinear Dynamics, vol. 75, no. 1-2, pp. 283-287, 2014.

[32] S. He, S. Banerjee, and B. Yan, "Chaos and symbol complexity in a conformable fractional-order memcapacitor system," Complexity, vol. 2018, pp. 1-15, Article ID 4140762, 2018.

[33] L. Yuan, S. Zheng, and Z. Alam, "Dynamics analysis and cryptographic application of fractional logistic map," Nonlinear Dynamics, vol. 96, no. 1, pp. 615-636, 2019.

[34] A. Al-Khedhairi, "Differentiated Cournot duopoly game with fractional-order and its discretization," Engineering Computations, vol. 36, no. 3, pp. 781-806, 2019.

[35] A.-A. Khennaoui, A. Ouannas, S. Bendoukha, G. Grassi, R. P. Lozi, and V.-T. Pham, "On fractional-order discretetime systems: chaos, stabilization and synchronization," Chaos, Solitons \& Fractals, vol. 119, pp. 150-162, 2019.

[36] L.-L. Huang, G.-C. Wu, D. Baleanu, and H.-Y. Wang, "Discrete fractional calculus for interval-valued systems," Fuzzy Sets and Systems, vol. 404, pp. 141-158, 2021.

[37] B. Xin, W. Peng, and Y. Kwon, "A discrete fractional-order Cournot duopoly game," Physica A: Statistical Mechanics and Its Applications, vol. 558, Article ID 124993, 2020.

[38] B. Xin, F. Cao, W. Peng, and A. A. Elsadany, "A Bertrand duopoly game with long-memory effects," Complexity, vol. 2020, Article ID 2924169, 7 pages, 2020.

[39] H. Wang and J. Ma, "Complexity analysis of a CournotBertrand duopoly game model with limited information," Discrete Dynamics in Nature and Society, vol. 2013, Article ID 287371, 6 pages, 2013.

[40] J. Čermák, I. Győri, and L. Nechvátal, “On explicit stability conditions for a linear fractional difference system," Fractional Calculus and Applied Analysis, vol. 18, p. 651, 2015.

[41] D. Mozyrska and M. Wyrwas, "Explicit criteria for stability of fractional $h$-difference two-dimensional systems," International Journal of Dynamics and Control, vol. 5, no. 1, pp. 4-9, 2017.

[42] R. Abu-Saris and Q. Al-Mdallal, "On the asymptotic stability of linear system of fractional-order difference equations," Fractional Calculus and Applied Analysis, vol. 16, no. 3, pp. 613-629, 2013.

[43] F. Chen, X. Luo, and Y. Zhou, "Existence results for nonlinear fractional difference equation," Advances in Difference Equations, vol. 2011, Article ID 713201, 2010.

[44] G. C. Wu and D. Baleanu, "Jacobian matrix algorithm for Lyapunov exponents of the discrete fractional maps," Communications in Nonlinear Science and Numerical Simulation, vol. 22, no. 1-3, pp. 95-100, 2015.

[45] A. Ouannas, A.-A. Khennaoui, S. Momani, and V.-T. Pham, "The discrete fractional duffing system: chaos, 0-1 test, C0 complexity, entropy, and control," Chaos: An Interdisciplinary Journal of Nonlinear Science, vol. 30, no. 8, Article ID 083131, 2020.

[46] A. Elsonbaty and A. A. Elsadany, "On discrete fractionalorder Lotka-Volterra model based on the Caputo difference discrete operator," The Mathematical Scientist, 2021. 